\title{
Acute coronary occlusion during percutaneous transluminal coronary angioplasty
}

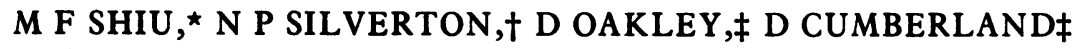 \\ From the ${ }^{\star}$ Queen Elizabeth Hospital, Bimingham; +Leeds General Infomary, Leeds; and the $\$$ Northern General \\ Hospital, Sheffield
}

SUMMARY Two hundred and forty percutaneous transluminal coronary angioplasty procedures were performed in three centres over a two year period. Acute occlusion of the vessel undergoing angioplasty was seen on $20(8 \%)$ occasions. The cause of occlusion was determined angiographically and in some cases confirmed at the time of emergency open heart surgery. The mechanism of coronary occlusion was arterial dissection in six cases, persisting coronary arterial spasm in seven, and coronary thrombosis in four. In three patients the mechanism could not be determined. Immediate reintroduction of a balloon dilatation catheter was attempted in 10 patients and resulted in restoration of adequate coronary flow in six. The remaining 14 patients underwent open heart surgery as an emergency procedure.

Percutaneous transluminal coronary angioplasty is now an accepted treatment for patients with angina and technically suitable coronary artery lesions. A major acute complication is coronary occlusion. Although this may be treated medically, emergency bypass grafting is often performed in the hope of myocardial salvage. In order to reduce the incidence of acute occlusion during percutaneous transluminal coronary angioplasty and rationalise its management, this review was undertaken to identify the mechanisms responsible for this complication.

\section{Patients and methods}

The first 240 percutaneous transluminal coronary angioplasty procedures in the three cardiothoracic centres were reviewed to determine the incidence of acute coronary occlusion. There were 209 patients (171 male and 38 female, a sex ratio of 4.5 to 1 ), whose ages ranged from 29 to 69 (mean 50) years. Table 1 shows the distribution of coronary arteries affected and the overall success and complications. All except five patients underwent angioplasty of one coronary artery per procedure.

Requests for reprints to Dr M F Shiu, Department of Cardiovascular Medicine, University of Birmingham, Queen Elizabeth Hospital, Birmingham B15 2TH.

Accepted for publication 9 April 1985
Table 1 Distribution of coromary arteries affected and outcome. Figures are numbers (\%)

\begin{tabular}{lll}
\hline & All procecures & Acute occlusions \\
\hline No of procedures & 240 & 20 \\
No of patients & 209 & 20 \\
Male/female (ratio) & $171 / 38(4 \cdot 5: 1)$ & $11 / 9$ \\
Age range (years) & $29-69$ (mean 50) & $38-63$ (mean 50) \\
Target vessels: & 147 & 12 \\
LAD & 64 & 7 \\
RCA & 13 & 1 \\
Cx & 10 & - \\
Vein grafts & $182(76)$ & 13 \\
Primary success & $16(6.6)$ & 2 \\
Emergency CABG & $3(1 \cdot 3)$ & \\
Death &
\end{tabular}

LAD, left anterior descending artery; RCA, right coronary artery; $\mathrm{Cx}$, circumflex artery; $\mathrm{CABG}$, coronary artery bypass graft.

\section{PERCUTANEOUS TRANSLUMINAL CORONARY} ANGIOPLASTY

Percutaneous transluminal coronary angioplasty was performed from the femoral route using a standard technique. ${ }^{2}$ Steerable balloon catheters with a freely movable guide wire were used in 128 of the 240 cases. All procedures were performed in the cardiac catheterisation laboratory under local anaesthesia. Before angioplasty patients received three days' treatment with aspirin $300 \mathrm{mg}$ daily, dipyridamole $100 \mathrm{mg}$ three times daily, nifedipine $10 \mathrm{mg}$ three times daily, and long acting nitrates. Intracoronary glyceryl trinitrate was given as $200-300 \mu \mathrm{g}$ in 2-3 ml of saline immediately before balloon passage and be- 
tween periods of balloon inflation as appropriate. In addition, nitrate was given during the procedure sublingually by transdermal patches or as an intravenous bolus of $5 \mathrm{mg}$ isosorbide dinitrate at the start of the procedure. The precise dosage and route were dictated by patient tolerance. Anticoagulation during the procedure was with heparin 10000 units intravenously at the start of the procedure with a further 5000 units after one hour if necessary.

\section{ANGIOGRAPHIC ANALYSIS}

Acute occlusion of the target vessel was defined angiographically as a total lack of contrast opacification beyond the point of occlusion or absolute stasis of coronary flow where some distal opacification was present. None of the cases under consideration had total occlusion before the procedure. In every instance the acute occlusion that followed the procedure was recognised before the patient was returned to the ward. Angiograms were reviewed retrospectively and the mechanism of occlusion decided by consensus using the following guidelines.

Coronary dissection-Patients with limited areas of coronary dissection related to balloon angioplasty not resulting in interference with coronary flow were excluded. Occlusion from dissection was recognised by multiple views of the obstructed vessel showing the presence of an extensive area of intimal elevation, extravasation of contrast medium, or persistent staining of the vessel wall (Figs. 1 and 2). The diagnosis of arterial dissection was generally confirmed at the time of emergency bypass grafting.

Coromary spasm-A tapering appearance of the site of occlusion in the absence of the above features suggestive of dissection was taken as probably due to coronary spasm (Fig. 3). Additional helpful features were partial and transient response to intracoronary nitrate injections. Only patients with occlusion despite repeated intracoronary nitrate administration were included in this study. In these cases no specific features were noted at the time of emergency surgery.

Coronary thrombosis-Intracoronary thrombus formation leading to occlusion was diagnosed by the presence of persistent intravascular filling defects associated with coronary stasis. Distal branches may be faintly opacified with central filling defects, giving a ghosting appearance. All cases categorised as being due to thrombosis were confirmed at emergency operation by the finding of thrombotic material in the vessel.

Others-Three cases of acute occlusion showed none of the above angiographic features.

\section{Results}

Acute coronary occlusion was found in 20 patients

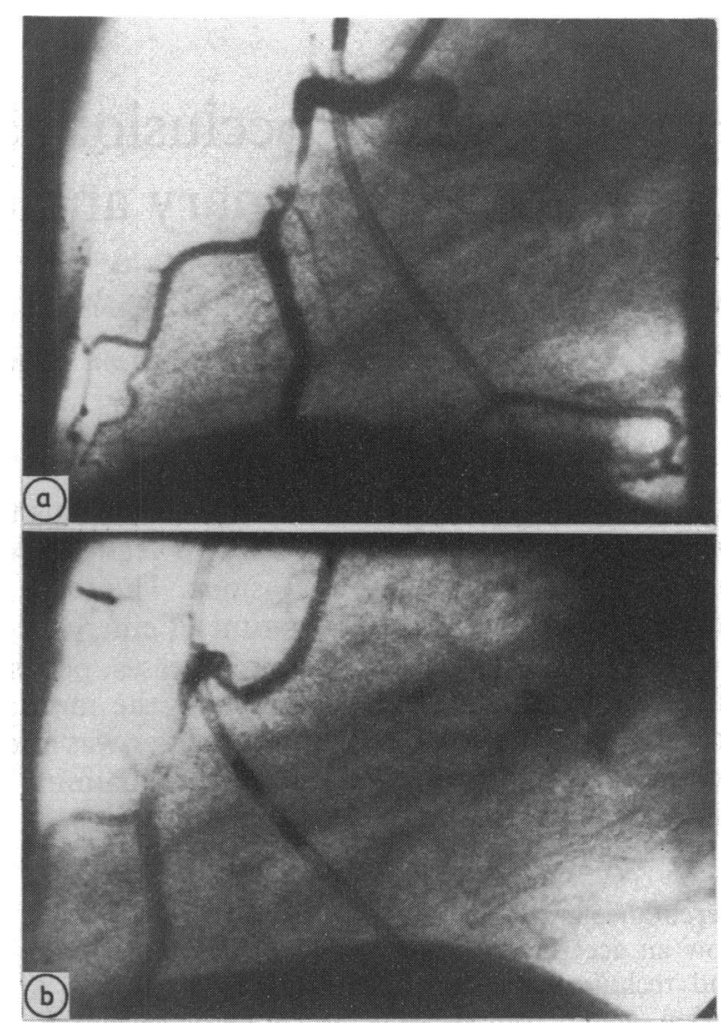

Fig 1 Angiograms showing acute coronary occhusion secondary to dissection in a man aged 48 (case 1). (a) Shows a limited dissection initially adjacent to the site of stenosis. Mirrutes later the dissection caused cessation of anterograde flow with only faint opacification of the distal homen (b). A repeat procechure was unsuccessful.

(nine women, $11 \mathrm{men}$ ) out of a total of 240 (8.3\%) procedures. Their mean age was 50 years, the age distribution being similar to that of the whole series of patients undergoing percutaneous transluminal coronary angioplasty. The distribution of affected arteries was left anterior descending 12 , right coronary artery seven, and circumflex artery one, which was also not different from that present in the whole group (Table 1). Acute occlusion accounted for 14 of all 16 emergency bypass graft operations and two of the three deaths.

\section{MECHANISM OF OCCLUSION}

The cause of acute occlusion was judged angiographically to be due to dissection in six cases, spasm in seven, and thrombosis in four. No specific angiographic features were found in three patients. Table 2 shows clinical features and outcome of the four groups of patients. Coronary artery bypass grafting was required for all four patients in whom occlusion was 


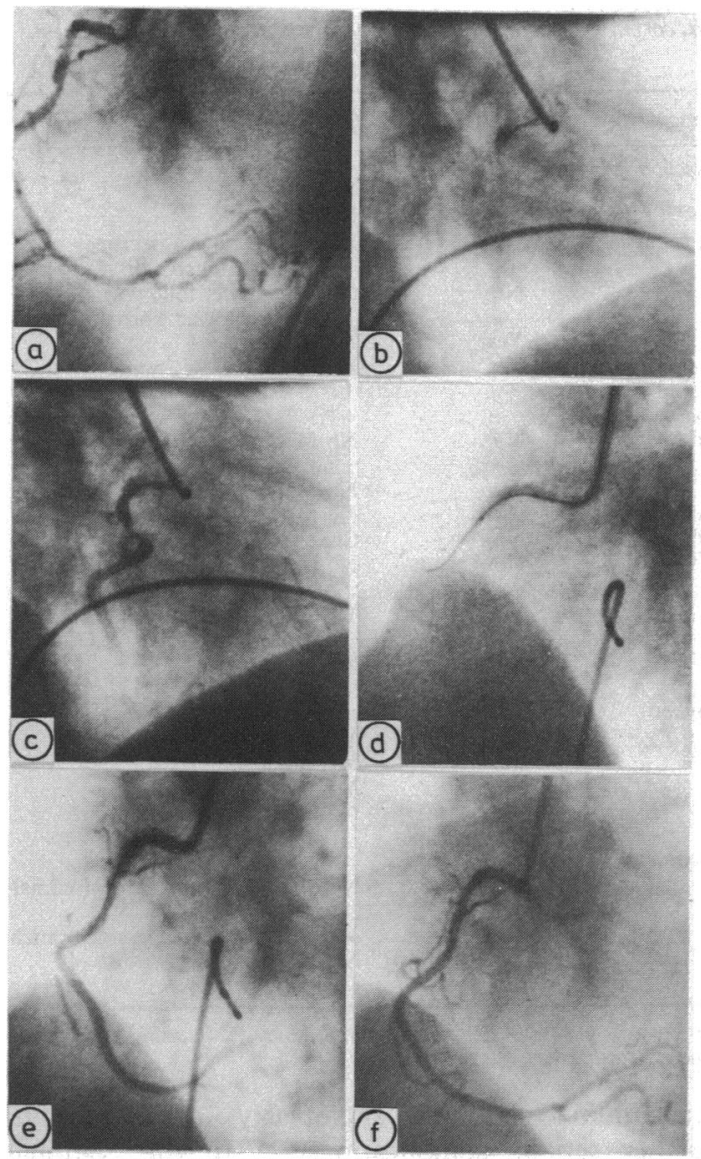

Fig 2 Angiograms showing acute coronary occhusion secondary to dissection in a waman aged 52 (case 4). (a) Shows a mid right coronary artery stenosis. During attempted passage of the balloon catheter contrast staining of the vessel wall was seen (b), and contrast injection showed occhusion with no effective anterograde flow (c). After a repeat procedure (d) anterograde flow was re-established (e), and a follow up angiogram at seven months showed no residual disease $(f)$.

due to thrombosis, in three in whom no definite angiographic features were seen, in four cases of dissection, and in three cases of coronary spasm. Of the two deaths, one occurred in a patient with dissection and one in a patient with spasm, but in the last instance the spasm was complicated further by the formation of thrombus distal to the site of spasm. Non-fatal myocardial infarction occurred in five patients ( $25 \%$ of those with occlusion). In only four (20\%) patients was clinical progress entirely uncomplicated after acute occlusion with neither myocardial infarct nor emergency bypass graft. Three had severe spasm and one had coronary dissection. All four had a

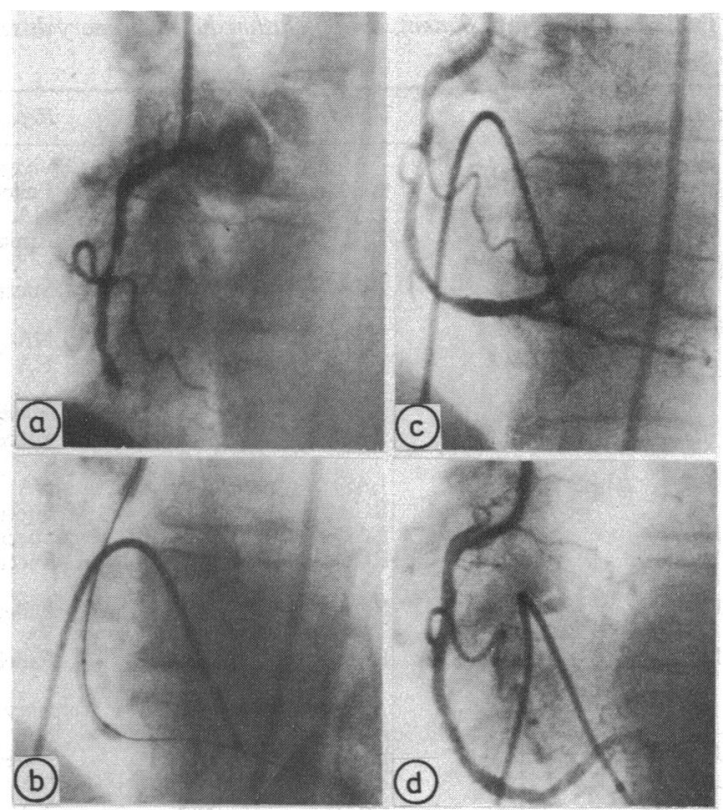

Fig 3 Angiograns showing acute occhusion coused by coronary spasm in a waman aged 58 (case 11). After angioplasty of two sequential right coronary artery stenoses distal occhusion occurred with a tapering appearance suggestive of spasm (a). Response to nitrate treament was inadequate, and a repeat procechare was performed (b). An inmediate $(c)$ and repeat angiogram at one week (d) showed a patent vessel.

successful immediate repeat angioplasty for acute occlusion.

\section{STEERABLE AND NON-STEERABLE SYSTEMS}

There was no apparent difference in the incidence of coronary occlusion whether steerable or non-steerable balloon catheters were used. Steerable systems were used in $54 \%$ of all patients undergoing the procedure (Table 1 ) and in 11 of the $20(55 \%)$ cases of acute occlusion. Successful recanalisation after occlusion was more likely with steerable systems, being successful in five out of seven attempts. Only one of the three attempts at recanalisation with the non-steerable system was successful.

\section{REPEAT ANGIOPLASTY}

A repeat procedure was attempted in three patients with dissection and was completely successful in one. In another patient (case 3, Table 2) apparent angiographic recanalisation was followed by death after 12 hours. From the postmortem findings it was thought likely that the false rather than the true lumen of the vessel was recanalised to provide a communication with the distal vessel. A repeat procedure was performed in five of the six cases of coronary spasm and 
Table 2 Outcome of patients with occlusion due to coronary dissection, coronary spasm, and coronary thrombosis, and miscellaneous couses

\begin{tabular}{|c|c|c|c|c|c|c|}
\hline Case No & Age/sex & Vessel & Castheter & Repeat angioplasty & $C A B G$ & Outcome/conments \\
\hline $\begin{array}{l}1 \\
2 \\
3\end{array}$ & $\begin{array}{l}48 / M \\
49 / F \\
47 / M\end{array}$ & $\begin{array}{l}\text { RCA } \\
\text { LAD } \\
\text { LAD }\end{array}$ & $\begin{array}{l}\mathbf{N}-\mathbf{S} \\
\mathbf{S}\end{array}$ & $\begin{array}{l}\text { Coronary dissection } \\
\text { Failed } \\
\text { NA } \\
\text { Apparent success }\end{array}$ & $\begin{array}{l}\text { Yes } \\
\text { Yes } \\
\text { No }\end{array}$ & \multirow{3}{*}{$\begin{array}{l}\text { No MI, home } \\
\text { No MI, home } \\
\text { Died at } 12 \text { hours, necropsy } \\
\text { showed extensive dissection } \\
\text { No MI, home; follow up at } 7 \\
\text { months showed normal RCA } \\
\text { No MI, home } \\
\text { Perioperative MI, home }\end{array}$} \\
\hline 4 & $52 / F$ & RCA & $\mathbf{S}$ & Success & No & \\
\hline $\begin{array}{l}5 \\
6\end{array}$ & $\begin{array}{l}55 / F \\
63 / M\end{array}$ & $\begin{array}{l}\text { LAD } \\
\text { LAD }\end{array}$ & $\mathrm{N}_{\mathrm{S}}^{\mathrm{N}}$ & $\begin{array}{l}\text { NA } \\
\text { NA }\end{array}$ & $\begin{array}{l}\text { Yes } \\
\text { Yes }\end{array}$ & \\
\hline 7 & $56 / M$ & LAD & N-S & $\begin{array}{l}\text { Coronary spasm } \\
\text { Successful }\end{array}$ & No & \multirow{4}{*}{$\begin{array}{l}\text { No MI, follow up angiogram } \\
\text { normal at } 6 \text { months } \\
\text { No MI, home } \\
\text { No MI, home } \\
\text { Clinical MI, home } \\
\text { No MI, follow up angiogram at } \\
\text { one week showed patent vessel } \\
\text { Thrombus distal to spasm site, } \\
\text { died } 12 \text { hours after CABG } \\
\text { No MI, home }\end{array}$} \\
\hline $\begin{array}{r}8 \\
9 \\
10 \\
11\end{array}$ & $\begin{array}{l}38 / M \\
39 / M \\
53 / M \\
58 / M\end{array}$ & $\begin{array}{l}\text { LAD } \\
\text { RCA } \\
\text { LAD } \\
\text { RCA }\end{array}$ & $\begin{array}{l}\mathrm{N}-\mathrm{S} \\
\mathrm{S} \\
\mathrm{S} \\
\mathrm{S}\end{array}$ & $\begin{array}{l}\text { NA } \\
\text { Successful } \\
\text { Successful } \\
\text { Successsful }\end{array}$ & $\begin{array}{l}\text { Yes } \\
\text { No } \\
\text { No } \\
\text { No }\end{array}$ & \\
\hline 12 & $57 / F$ & RCA & N-S & Failed & Yes & \\
\hline 13 & $44 / M$ & RCA & $\mathbf{S}$ & Failed & Yes & \\
\hline $\begin{array}{l}14 \\
15 \\
16 \\
17\end{array}$ & $\begin{array}{l}62 / M \\
41 / F \\
45 / F \\
56 / F\end{array}$ & $\begin{array}{l}\text { LAD } \\
\text { LAD } \\
\text { RCA } \\
\text { LAD }\end{array}$ & $\begin{array}{l}\mathbf{N}-\mathbf{S} \\
\mathbf{S} \\
\mathbf{N}-S \\
\mathrm{~N}-\mathrm{S}\end{array}$ & $\begin{array}{l}\text { Coronary thrombosis } \\
\text { NA } \\
\text { Failed } \\
\text { NA } \\
\text { NA }\end{array}$ & $\begin{array}{l}\text { Yes } \\
\text { Yes } \\
\text { Yes } \\
\text { Yes }\end{array}$ & $\begin{array}{l}\text { MI, home } \\
\text { MI, home } \\
\text { No MI, home } \\
\text { No MI, home }\end{array}$ \\
\hline 18 & $56 / M$ & LCx & $\mathrm{N}-\mathrm{S}$ & $\begin{array}{l}\text { Miscellaneous causes } \\
\text { NA }\end{array}$ & Yes & \multirow{2}{*}{$\begin{array}{l}\text { No MI, balloon inflated proximal } \\
\text { to stenosis } \\
\text { MI, balloon inflated in side branch } \\
\text { No MI, no obvious cause of } \\
\text { occlusion }\end{array}$} \\
\hline $\begin{array}{l}19 \\
20\end{array}$ & $\begin{array}{l}49 / M \\
36 / M\end{array}$ & $\begin{array}{l}\text { LAD } \\
\text { LAD }\end{array}$ & $\begin{array}{l}\mathbf{S} \\
\mathbf{S}\end{array}$ & $\begin{array}{l}\text { NA } \\
\text { NA }\end{array}$ & $\begin{array}{l}\text { Yes } \\
\text { Yes }\end{array}$ & \\
\hline
\end{tabular}

N-S, non-steerable; S, steerable (balloon catheter system); CABG, coronary artery bypass grafting (emergency); NA, not attempted; MI, myocardial infarct; LAD, left anterior descending; RCA, right coronary artery; LCx, left circumflex.

was successful in four. Although one patient had myocardial infarction, none of the four required bypass grafting. Follow up for a mean of seven months after angioplasty showed good clinical results (Table 2). Of the two failed repeated procedures in this category, in one patient (case 12, Table 2) there was angiographic evidence of distal thrombosis formation secondary to unrelieved spasm despite repeated balloon dilatation and maximal treatment with nitrate and a calcium antagonist. This patient died despite emergency bypass grafting.

Repeat angioplasty was attempted in one case of coronary occlusion due to thrombus formation and was unsuccessful. All four patients with thrombotic occlusion and the three with non-specific occlusion underwent bypass grafting, and in these two subgroups there were no hospital deaths. In two patients review of the angiograms suggested that the cause of the occlusion was malposition of the balloon at the time of inflation, either proximal to the lesion or in an immediate side branch.

\section{Discussion}

Acute coronary occlusion at the time of percutaneous transluminal coronary angioplasty often leads to further serious complications. ${ }^{3-s}$ In the National Heart, Blood and Lung Institute series reported by Cowley et al coronary occlusion accounted for $64 \%$ of myocardial infarcts, $93 \%$ of emergency bypass operations, and $63 \%$ of inpatient deaths. ${ }^{5}$ Of the 20 cases reported here, 14 required emergency surgery, five sustained clinical myocardial infarctions, and two died. Only four (20\%) patients had coronary occlusions resolved without any major complications or surgery.

Simple occlusion without a definitive diagnosis of spasm or dissection occurred between $4 \%$ and $5 \%$ in the series reported by Kent et $\mathrm{al}^{3}$ and Dorros et al. ${ }^{4}$ When occlusion due to any cause is included, the incidence is between $9 \%$ and $12 \%$ for these large series of cases. We defined occlusion complicating percutaneous transluminal coronary angioplasty as either the complete absence of vessel opacification by contrast injection or a lack of anterograde flow in an opacified vessel. Our incidence of $8.3 \%$ is comparable to that in previous reports.

Female patients were at higher risk from occlusion, occurring in nine out of $39(23 \%)$ instances, whereas the risk in male patients was only $6 \cdot 4 \%$. Four out of 
six cases of occlusion from vessel dissection affected female patients. Age and the vessel involved did not appear to be a relevant factor. This observation again supports previous experience that the overall risk of percutaneous coronary angioplasty is higher in women. ${ }^{4}$

In our experience it is often difficult to establish the actual cause of acute occlusion at the time of the complication, and some of the cases were classified retrospectively with the help of full screen projection of the cineangiograms. We have found the need for several projection angles to identify features such as intimal elevation in dissection and filling defects in thrombotic occlusion. From our limited experience, angiographic diagnosis of the mechanism of occlusion seems to be helpful in the immediate management of the patient.

Emergency bypass surgery was necessary in all our cases of thrombotic occlusion. Although the use of streptokinase may prove useful, so far it has been used only to gain time to prepare for emergency surgery. ${ }^{6}$ Some of our cases were due to prolonged procedures and too little anticoagulation. With rigid adherence to the recommended doses ${ }^{7}$ and shorter procedure time with increased operator experience this complication may be reduced.

Our experience of successful immediate repeat angioplasty in four out of six attempts in dealing with occlusion due to spasm accords with Hollman et al's report that emergency bypass surgery can often be avoided this way. ${ }^{7}$ The role of repeat angioplasty in occlusion due to dissection is less well established. Repeat balloon inflation may maintain anterograde flow by pushing back the loose intimal flap. A major hazard in this approach is canalisation of the false passage resulting in worsening of the dissection. The steerable system does allow less traumatic exploration of the vessel with soft tipped wires than the balloon catheter and should be exclusively used for this purpose.
In conclusion, we found acute coronary occlusion of the target vessel to be the single most important cause of morbidity and mortality with percutaneous transluminal coronary angioplasty. Angiographic diagnosis of the actual mechanism of occlusion was useful as it has a bearing on the subsequent management. More experience is required to define the role of immediate repeat angioplasty, but it appears to be indicated in cases due to spasm. Strenuous efforts should be made towards the prevention of occlusion from any cause complicating coronary angioplasty.

\section{References}

1 Gruentzig A. Transluminal dilatation of coronary-artery stenosis [Letter]. Lancet 1978; i: 263.

2 Simpson JB, Baim DS, Robert EW, Harrison DC. A new catheter system for coronary angioplasty. $\mathrm{Am} \mathcal{F} \mathrm{Car}$ diol 1982; 49: 1216-22.

3 Kent KM, Bentivoglio LG, Block PC, et al. Percutaneous transluminal coronary angioplasty: report from the Registry of the National Heart, Lung, and Blood Institute. Am f Cardiol 1982; 49: 2011-20.

4 Dorros G, Cowley MJ, Simpson J, et al. Percutaneous transluminal coronary angioplasty: report of complications from the National Heart, Lung, and Blood Institute PTCA Registry. Circulation 1983; 67: 723-30.

5 Cowley MJ, Dorros GD, Kelsey SF, Van Raden M, Detre KM. Acute coronary events associated with percutaneous transluminal coronary angioplasty. $\mathrm{Am} \mathcal{F} \mathrm{Car}$ diol 1984; 53: 12c-6c.

6 Schofer J, Krebber HJ, Bleifeld W, Mathey DG. Acute coronary artery occlusion during percutaneous transluminal coronary angioplasty: re-opening by intra-coronary streptokinase before emergency coronary artery surgery to prevent myocardial infarction. Circulation 1982; 66: 1325-31.

7 Hollman J, Gruentzig AR, Douglas JS Jr, King SB, Ischinger T, Meier B. Acute occlusion after percutaneous transluminal coronary angioplasty-a new approach. Circulation 1983; 68: 725-32. 